\title{
CONCEPÇÕES DOCENTES ACERCA DAS ESSENCIALIDADES DA PRODUÇÃO TEXTUAL ESCRITA
}

\author{
Eloara Tomazoni* \\ Mary Elizabeth Cerutti-Rizzatti**
}

Resumo: O presente estudo tem como tema a produção textual escrita. Consiste em um estudo de caso em que se propõe, à luz de teorizações do ideário histórico-cultural que tratam do tema na área da Linguística Aplicada e por meio de entrevistas realizadas com 47 professores de Língua Portuguesa em atividade nos terceiro e quarto ciclos em escolas da rede estadual de ensino, a descrever analiticamente concepções docentes no que se refere às essencialidades da produção textual escrita. Os resultados apontam reverberações do ideário histórico-cultural nas concepções docentes; entretanto tais reverberações se distinguem substancialmente dos pressupostos presentes nos documentos norteadores da educação e na literatura da área, o que sinaliza para não apropriação efetiva desse ideário dentre os participantes de pesquisa.

Palavras-chave: Produção textual escrita. Ideário histórico-cultural. Concepções docentes.

\begin{abstract}
The present study has as theme the written text production. It consists in a study case in wich it is proposed, in lights of theorizations of the cultural-historical ideal that treats the theme in the Applied Linguistics and by interviews with in-service 47 Portuguese teachers in the third and the fourth cycles in state schools, to describe analytically teacher conceptions about the essentialities of the written text production. The results point to reverberations of the cultural-historical ideal in the teacher conceptions; however the content of these reverberations is substantially distinguished of the assumptions present in the guiding documents of education and in the related literature about the written text production, which signalizes for the non effective appropriation of this ideal among the research participants.
\end{abstract}

Keywords: Written text production. Cultural-historical ideal. Teacher conceptions.

\footnotetext{
* Doutoranda do Programa de Pós-graduação em Linguística da Universidade Federal de Santa Catarina (UFSC). Contato: eloara_tomazoni@hotmail.com

** Professora Doutora do Programa de Pós-graduação em Linguística da Universidade Federal de Santa Catarina. Contato: ma.rizzatti@gmail.com
} 


\section{Introdução}

O tema deste artigo são concepções docentes acerca da produção textual escrita ${ }^{l}$. Propomo-nos, à luz do ideário histórico-cultural presente nas teorizações que tratam do tema no campo da Linguística Aplicada e do conteúdo de documentos oficiais em nível federal e estadual, a descrever analiticamente concepções de professores de Língua Portuguesa acerca das essencialidades do ato de produzir um texto escrito.

Ao descrever analiticamente tais concepções no que se refere ao domínio ontológico, entendido como a visão das propriedades gerais, da essência da atividade de produção textual escrita, objetivamos responder à seguinte questão de pesquisa: Quais as concepções dos professores participantes do estudo acerca das essencialidades da produção textual escrita? O olhar sobre essa questão teve como ancoragem o seguinte questionamento: É possível depreender, nessas concepções, implicações do ideário histórico-cultural do modo como esse ideário se constitui na literatura contemporânea sobre ensino de língua materna e do modo como está materializado nos PCNs (BRASIL - PCNs LP, 1998) e na Proposta Curricular de Santa Catarina (SC - PC - LP, 1998)?

Cabe ressaltar que estamos cientes do risco que corremos quando nos lançamos a analisar reverberações do ideário histórico-cultural nas representações dos professores participantes deste estudo acerca da produção textual escrita, tomando-a na essencialidade de que se reveste esse ato humano, pois podemos ser instados a pensar sobre eventuais dificuldades dos participantes de pesquisa em responder a questões dessa ordem. Reconhecemos essas dificuldades porque lidar com esse recorte implica lidar com categorizações abstratas, mas, em nossa compreensão, isso não pode nos demover de uma interlocução com esse objetivo, ou seja, depreender representações docentes sobre a produção textual escrita na abstração ontológica sobre a qual essa depreensão se sustenta. Lidar com categorias abstratas é uma contingência de estudos teóricos, o que uma epistemologia focada no uso não tem de negar por contingência lógica. Aliás, dessas representações seguramente derivam ações metodológicas;

\footnotetext{
${ }^{1}$ Este trabalho consiste em um recorte de dissertação de mestrado intitulada "Produção textual escrita e escola: um olhar sobre ancoragens de concepções docentes" (TOMAZONI, 2012).
} 
afinal, por exemplo, uma resposta que enuncie que "a produção textual escrita é uma forma de interação com o outro" seguramente terá desdobramentos metodológicos distintos de uma resposta que enuncie que a "produção textual escrita é a veiculação do pensamento".

Assim, a pesquisa se constitui em um estudo de caso com abordagem qualitativa. Foi operacionalizada por meio de entrevistas realizadas com 47 professores em atividade, no ano de 2011, nos terceiro e quarto ciclos das escolas da rede estadual de ensino situadas no município de Florianópolis - SC. Dentre as questões que os professores responderam nessa entrevista, iremos analisar, para as finalidades deste estudo, a primeira questão: "Para você, o que é produção textual escrita?".

Considerando nosso instrumento de geração de dados e a quantidade de participantes, ressaltamos que embora este estudo se constitua de uma abordagem qualitativa, nos valemos de abordagem quantitativa complementar, tal qual defende Baquero (2009), pois no percurso analítico, depreendemos tendências em se tratando das concepções dos participantes de pesquisa e, para tal, assumimos que o estamos fazendo sob uma ótica interpretativista (MASON, 1996) porque se trata de sínteses derivadas de ausculta analítica atenta - e sintetizar implica interpretar - de um universo de 47 entrevistas.

Com vistas a tal discussão, este artigo conta com duas seções de conteúdo. Na primeira, descrevemos, por meio de um olhar pontual, o perfil dos docentes participantes deste estudo. Na segunda seção, passamos a responder a questão de pesquisa que move esta análise, portanto, descrevemos analiticamente as concepções docentes depreendidas por meio das entrevistas realizadas acerca das essencialidades da produção textual escrita. Ressaltamos que optamos por não desenvolver uma seção específica referente às bases teóricas que ancoram este estudo, pois no decorrer da seção de análise embasamos teoricamente a discussão acerca das concepções docentes depreendidas.

\section{Um olhar pontual sobre o perfil dos professores participantes do estudo}

Descrevemos analiticamente, nesta seção, os professores participantes do estudo antes de prosseguirmos com a análise dos dados, pois entendemos necessário explicitar, ainda que genericamente, quem são 
esses professores para podermos apresentar quais suas concepções acerca das essencialidades da produção textual escrita.

Nosso campo de estudo foi composto pelas 29 escolas pertencentes à rede estadual de ensino que possuem terceiro e quarto ciclos e estão situadas no município de Florianópolis - SC. Nessas 29 escolas, havia 57 vagas para professores de Língua Portuguesa nos anos finais do Ensino Fundamental no ano de 2011. Dessas 57 vagas, quatro não estavam preenchidas e um mesmo docente ocupava duas vagas, totalizando 52 professores em atividade na rede estadual de ensino nos terceiro e quarto ciclos, na disciplina de Língua Portuguesa. Desses 52 professores em atividade, 47 formaram o grupo dos participantes do presente estudo, totalizando 90,4\%.

Optamos por dividir esta seção acerca do perfil dos docentes participantes do estudo em duas subseções para melhor visualização dos dados. Na primeira subseção, descrevemos analiticamente os dados referentes ao sexo ${ }^{2}$; faixa etária; tempo de magistério; número de escolas, turmas e alunos; tipo de contrato estabelecido com a Secretaria de Estado da Educação - SED; e carga horária dos professores. Já na segunda subseção, agrupamos os dados que se referem à formação desses docentes no que diz respeito à graduação; pós-graduação, lato e stricto sensu; e formação continuada.

\subsection{Caracterização genérica dos professores participantes do estudo}

Em se tratando do grupo de 47 professores participantes, atuantes na disciplina de Língua Portuguesa nos terceiro e quarto ciclos das 29 escolas da rede estadual de ensino do município de Florianópolis, Santa Catarina, no ano de 2011, os dados nos permitem observar que 42 dentre esses docentes, são do sexo feminino, totalizando $89,4 \%$, e cinco são do sexo masculino, o que constitui $10,6 \%{ }^{3}$.

A prevalência de docentes do sexo feminino entre os participantes de nosso estudo converge com teorizações a respeito de a profissão do magistério ser exercida predominantemente por mulheres e a diferenciação

\footnotetext{
$\overline{2}$ Optamos por sexo ao invés de gênero, uma vez que o termo gênero, no âmbito deste estudo, tem conceituação distinta, o que nos traria um custo explicativo ao longo do texto, processo que entendemos desnecessário.

${ }^{3}$ A despeito dessa prevalência feminina, tratamos o grupo em estudo como os professores, por força da tradição linguística.
} 
entre os sexos masculino e feminino no que diz respeito a essa atividade profissional, a exemplo de estudos de Rabelo e Martins (2006). Segundo os autores, "[...] a feminização no magistério não se resume ao aspecto quantitativo das mulheres, [número] que aumentou nos âmbitos educacionais, mas também à concepção docente [que vige] na sociedade, que [essa profissão] está sempre associada às características femininas" (RABELO; MARTINS, 2006, p. 6168).

Pelo que podemos observar em nossos dados, embora mudanças tenham ocorrido nesse paradigma, a profissão docente, ao que parece, ainda está estreitamente vinculada ao sexo feminino; nossos dados corroboram esse quadro. Importa ainda observar a faixa etária dos participantes deste estudo. A maior parte dos docentes - 59,6\% - tem mais de quarenta anos de idade, e $36,2 \%$ está na faixa entre 25 e quarenta anos.

Um componente intensificador da rotina diária relacionada à atuação profissional desses professores é a carga horária que cumprem. Neste estudo, 51,1\% dos professores entrevistados lecionam quarenta horas semanais, o que nos leva a inferir que esses docentes não dispõem de tempo para estudos teóricos acerca do processo de ensino de Língua Portuguesa bem como para planejamento das aulas, visto que, segundo informações fornecidas por eles no decorrer da realização das entrevistas, aqueles que trabalham quarenta horas lecionam 38 aulas semanais, ou seja, não parece haver nenhum período dessa carga horária destinado ao planejamento das aulas, cursos de formação continuada ou quaisquer outras atividades relacionadas à prática pedagógica ${ }^{4}$.

Outro fator implicado na atuação profissional desses docentes, relacionado à carga horária é a quantidade de escolas e de turmas em que esses professores lecionam e a quantidade de alunos, em média, em cada turma. A maioria dos professores participantes deste estudo - 55,3\% - leciona em cinco a dez turmas (contando com turmas de outras escolas municipais ou privadas - em que leciona) e 51,1\% dizem haver, em média, vinte a trinta alunos nas turmas em que lecionam. Esses dados evidenciam uma realidade que inferimos ser de relevante impacto nas considerações acerca das concepções docentes que pudemos depreender por meio deste

\footnotetext{
${ }^{4}$ Cabe salientar que em uma escola, os professores nos informaram participarem de reuniões semanais de duas horas com o objetivo de discutir questões relacionadas à disciplina de Língua Portuguesa com colegas da área; o enfoque burocrático, porém, segundo alguns deles, tende a prevalecer nesses encontros.
} 
estudo. A carga de trabalho de um professor pode se tornar um impedimento para leituras teóricas sobre temas da área, tanto quanto para frequência a cursos de formação continuada, eventos de curta duração, bem como para participação em planejamentos em conjunto ou projetos interdisciplinares.

Ainda em relação aos elementos que acabamos de discutir, outro fator relevante em nosso estudo é o tipo de contrato - se se trata de profissionais efetivos ou contratados temporariamente (ACT) - que os professores participantes desta pesquisa tinham estabelecido com a Secretaria de Estado da Educação, no ano do estudo. Nas respostas a essa questão, pudemos depreender que um número expressivo dentre os 47 professores participantes deste estudo - 48,9\% - disseram ser contratados em caráter temporário (ACT). Para Lapo e Bueno (2003), o número elevado de professores contratados em caráter temporário pode ser um dos responsáveis pela alta rotatividade dos profissionais docentes na escola, já que todos os anos esses professores são desligados do quadro docente do estado e voltam no ano seguinte, caso ainda haja vaga disponível. De acordo com os autores, "Essa rotatividade gera uma falta de vínculo do professor com a escola, o que pode trazer graves consequências para um tão almejado ensino de qualidade" (LAPO; BUENO, 2003, p. 71).

Entendemos que na realidade de sala de aula, o fato de os professores contratados em caráter temporário não ficarem muito tempo na mesma escola e nem com as mesmas turmas dificulta o estabelecimento de vínculos entre professores e alunos, bem como inviabiliza um conhecimento mais efetivo acerca da realidade sociocultural de que faz parte a escola. Considerando que o objetivo da disciplina de Língua Portuguesa, em nossa concepção e à luz de Street (2003) e Kalantzis e Cope (2006), é ressignificar as práticas de uso da língua dos alunos, tal processo só pode, realmente, ocorrer se o professor tiver conhecimento dos eventos de letramento dos quais seus alunos participam no cotidiano de modo a depreender as práticas de letramento que os caracterizam, para, dessa maneira, buscar a hibridização entre os universos local e global, tal qual registra Street (2003).

Por fim, além das caracterizações descritas nesta subseção, ainda nos resta apresentar o tempo de magistério dos professores participantes do estudo. A maior parte deles - 42,6\% - leciona há até dez anos. Considerando que os documentos oficiais de Língua Portuguesa - Parâmetros Curriculares Nacionais (BRASIL - PCNs LP, 1998) e Proposta Curricular de Santa 
Catarina (SC - PC - LP, 1998) - foram publicados em 1998, inferimos que esses $42,6 \%$ dentre os professores, que lecionam há até dez anos, tiveram contato com esse ideário nas escolas por meio das discussões acerca dos documentos oficiais de educação.

Ao que parece, as discussões sobre as novas propostas para o ensino de Língua Portuguesa têm relevante influência nas concepções docentes, se pensarmos no momento em que esses professores começaram a lecionar e ainda lecionam. É possível observar, nas concepções docentes que pudemos depreender por meio das entrevistas realizadas, conforme descrevemos analiticamente na próxima seção deste artigo, que essas discussões percorrem a esfera escolar e ecoam de algum modo nas concepções docentes depreendidas.

Além dos dados que caracterizam genericamente o perfil dos professores participantes deste estudo, descritos nesta subseção, consideramos que os dados apresentados na subseção a seguir, relativos à formação desses docentes, também têm relação direta nas concepções depreendidas, pois formam com aqueles um conjunto inter-relacionado de elementos que incidem sobre a profissão docente conjuntamente, tal qual propõe Basso (1998), perspectiva que corroboramos, embora tenhamos separado os dados para fins analíticos.

\subsection{Formação dos professores participantes do estudo}

Nesta subseção, buscamos descrever analiticamente os dados gerados relacionados à formação dos professores participantes deste estudo. Pudemos depreender que 43 dos 47 professores entrevistados já concluíram o curso de graduação e a maioria - 46,5\% - o concluiu entre os anos 1990 e 2000 , e número também elevado - 37,2\% - o fez posteriormente a isso. Isso nos leva a um percentual de $83,7 \%$ dos participantes de estudo que já concluíram o curso de graduação cuja formação inicial é, em boa medida, coetânea ou posterior à organização e à publicação dos documentos oficiais e das propostas acadêmicas entendidas, aqui, como o ideário históricocultural prevalecente no pensamento nacional sobre ensino de Língua Portuguesa na contemporaneidade.

Inferimos, portanto, que os docentes que concluíram o curso de graduação nessa época, em tese, poderiam ter tido contato com esse ideário na universidade e, desse modo, as discussões que ancoram a proposta do ensino operacional e reflexivo da linguagem (GERALDI, 1997 [1991]) 
poderiam ou deveriam, também em tese, estar presentes nas concepções dos docentes participantes deste estudo, mais precisamente porque

Já a partir do começo dos anos oitenta, expandem-se as linhas editoriais de bibliografia crítica, organizam-se encontros de especialistas, amplia-se o oferecimento de cursos de extensão e formação do professor e desenvolve-se uma rede de formação de opinião que tinha como base a importância da promoção de leitura [e da escrita]. Com a eleição de políticos de oposição para prefeituras municipais e governos de estado, surgem projetos mais amplos, com a elaboração de currículos alternativos e textos de apoio ao professor (guias curriculares de secretarias de educação). (BRITTO, 1997, p. 102)

Ainda no âmbito da formação inicial dos docentes participantes deste estudo, é importante ressaltar que $44,2 \%$ dos professores concluiu o curso de graduação na Universidade Federal de Santa Catarina - UFSC -, instituição à qual este estudo está vinculado. Inferimos que essa universidade teve papel fundamental na formação inicial desses docentes, visto que é por meio do curso de Letras Português dessa instituição que $44,2 \%$ desses docentes foram habilitados a atuar no magistério. Em nosso entendimento, esse fato corrobora a tese de que essa instituição, por meio da formação inicial desses docentes, exerceu importante influência nas concepções depreendidas neste estudo.

Entendemos que além da formação na graduação, outro aspecto relevante a ser analisado é a formação em pós-graduação dos docentes participantes desta pesquisa. Dos 47 professores participantes, apenas 19,4\% têm formação em pós-graduação lato sensu na área de ensino de Língua Portuguesa. Esses professores disseram ter realizado o curso de especialização com foco em Metodologia do Ensino da Língua Portuguesa e Leitura. Já 80,6\% dos professores o fizeram em outras áreas.

No que diz respeito à pós-graduação stricto sensu, quatro professores apresentavam tal formação, no entanto nenhum dos docentes a realizou com foco no ensino de língua materna, mas em outras áreas - Literatura; Estudos da Linguagem; Mídia e Conhecimento e Língua e Literatura Espanhola. Em nosso entendimento, esse é um dado relevante na análise das concepções docentes depreendidas por meio das entrevistas, visto que, em um grupo grande de docentes, há um número relativamente pequeno com formação em nível de pós-graduação na área.

Ainda, é importante ressaltar que a maior parte dos docentes - 
$57,4 \%$ - diz não participar de cursos de formação continuada, enquanto $42,6 \%$ dizem participar de cursos dessa natureza. Em nosso entendimento, esse tipo de curso, independentemente de avaliações sobre seus resultados, tende a estabelecer influência direta nas concepções dos professores. Nessa perspectiva, comungamos com Silveira $(2009$, p. 10816) a percepção de que

[...] é importante rediscutir a formação docente, tanto no que tange à formação inicial quanto à formação continuada, de maneira a garantir aos professores um espaço para a reflexão sobre os parâmetros teórico-metodológicos que norteiam a disciplina, mas também sobre a elaboração didáticopedagógica dos conteúdos.

Entendemos que os cursos de formação continuada, assim como os cursos de formação inicial, são relevantes para que o ideário que vem sendo discutido na esfera acadêmica desde a década de oitenta e que consta na proposta dos documentos oficiais norteadores da educação possa, de fato, ser objeto de apropriação e reflexão por parte desses professores.

\section{Concepções docentes acerca das essencialidades da produção textual escrita}

Com o objetivo de descrever analiticamente as concepções dos professores participantes deste estudo acerca das essencialidades da produção textual escrita, formulamos a questão: "Para você, o que é produção textual escrita?", como mencionamos anteriormente. Por meio das respostas dos professores a essa questão, pudemos depreender uma concepção prevalecente da produção textual escrita como uma forma de o ser humano poder expressar seus conhecimentos, suas ideias, seus pensamentos sobre determinado assunto ou tema como mostramos a seguir. Dentre o que chamamos de outras concepções, aparecem representações como: a produção de textos escritos comprometida com a estrutura do texto; tal produção como forma de comunicação; ou como uma atividade em que há um objetivo claro, um destinatário, e acontece em determinado gênero discursivo; e, ainda tal produção como uma forma de ascensão social, de compreender melhor o mundo. A Tab.1 a seguir constitui uma tentativa de concepção e pulverização de outras tantas representações. 
Tabela 1 - O que é produção textual escrita

\begin{tabular}{c|c|c}
\hline Concepção & $\begin{array}{c}\text { Quantidade } \\
\text { de } \\
\text { Professores }\end{array}$ & $\%$ \\
\hline Expressão do pensamento & 37 & 78,7 \\
Outras concepções & 10 & 21,3 \\
\hline \multicolumn{2}{c}{ Total Fonte: Construção da autora } \\
\hline \multicolumn{2}{c}{$\mathbf{1 0 0 , 0}$} \\
\hline
\end{tabular}

Nas respostas a essa questão, como podemos observar na Tab.1, a leitura interpretativa das enunciações dos professores faz-nos inferir que a maioria dos docentes participantes do estudo - 78,7\% - relaciona o processo de produção textual escrita a concepções comprometidas com expressão do pensamento. Como exemplo de enunciações que nos levaram a depreender essa concepção, podemos visualizar o excerto a seguir.

(1)A princípio, [produzir um texto escrito é] expor o que a pessoa adquiriu até então como conhecimento intelectual. Isso ela vai conseguir a partir das experiências adquiridas até então. Qualquer forma de expressão na escrita é o resultado do que ela aprendeu até ali. (AS ${ }^{5}$, entrevista realizada em 02/08/2011, ênfase nossa) ${ }^{6}$

Entendemos possível observar nesse excerto a concepção de que quando produzimos um texto escrito estamos expressando nossos conhecimentos intelectuais adquiridos até o momento, conforme o trecho destacado. Essa concepção de produção textual escrita parece se aproximar da concepção de linguagem denominada por Bakhtin [Voloshinov] (1999 [1929]) como sendo subjetivismo individualista. Segundo o autor, nessa

5 Por questões de ética, optamos por referir os participantes pelas iniciais de seus nomes devidamente desordenadas. Desse modo, se o professor se chama João Carlos da Silva, por exemplo, usaremos uma designação como CSJ, em um processo randômico de quebra da identificação dos participantes de pesquisa.

6 Manteremos, ao longo dos excertos, as marcas da oralidade nas falas. Faremos ajustes apenas quando a configuração da fala puder expor de algum modo a face do professor participante da pesquisa. 
psíquica dos falantes. Bakhtin [Voloshinov] (1999 [1929]) aponta que, nessa concepção, há o entendimento do ato de fala, verdadeiro núcleo na realidade linguística, como criação individual, ou seja, monológico. $\mathrm{O}$ autor ressalta que os adeptos dessa corrente entendem a atividade de linguagem como expressão do psiquismo individual, na compreensão de que tal psiquismo constituiria a fonte da língua, processo em que as leis da criação linguística estariam submetidas às leis da psicologia individual. Nesse sentido, produzir um texto escrito seria expressar, via modalidade escrita da língua, ideias, pensamentos, opiniões que foram apreendidas por meio de fontes diversas, como no caso destes excertos: (2) "Eu acho que a produção textual escrita é a expressão do pensamento, daquilo que eles já tiveram. Uma prévia de um conteúdo, de uma leitura, de uma poesia. Alguma coisa nesse sentido". (MSAS, entrevista realizada em 04/08/2011); (3) "É expressar o que se pensa, o que se sente, o que se produziu em termos de raciocínio". (FOAC, entrevista realizada em 02/09/2011).

Ao analisar criticamente o subjetivismo individualista e também outra corrente que denomina objetivismo abstrato, na qual a língua é entendida como sistema abstrato das formas linguísticas, Bakhtin [Voloshinov] (1999 [1929]) entende que essas correntes não conseguem explicar a complexidade social, ideológica e discursiva da realidade linguística. Para o autor, o foco se constitui não em negar o universo cognitivo, em que a linguagem se presta, sim, à organização do pensamento, mas transcender essa compreensão, entendendo que ela é instrumento fundante da interação social, conforme, acrescentamos, propõe Vygotsky (2007 [1978]).

$\mathrm{Na}$ concepção que depreendemos das entrevistas, segundo a qual produzir um texto escrito seria expressão do pensamento, há a compreensão de que textualizar seria registrar o que produzimos intelectualmente, conforme explicitado no próximo excerto.

(4) Bom, para um aluno chegar a uma produção textual escrita, ele já teve previamente uma ampliação de seu conhecimento de mundo, ou mediante aquele tema que vai ser trabalhado. Para mim, a produção textual é o resultado de tudo aquilo que ele absorveu diante daquilo que lhe foi passado, pesquisado, mostrado. Para mim, é o resultado de... Isso é produção textual. Vou colocar no lápis, vou registrar aquilo que já está completo na minha mente. Eu não posso produzir algo sem ter algo na minha mente. (CWSL, entrevista realizada em 06/09/2011, ênfase nossa)

que o entendimento da produção de textos escritos como expressão do pensamento aproxima-se muito significativamente de bases do modelo 
autônomo de letramento, focado na cognição e na imanência da modalidade escrita; distingue-se, pois, do modelo ideológico, segundo o qual a escrita se presta ao uso social nas interações humanas e, como tal, também pode ser entendida como instituidora dessas interações, conforme inferimos em Bakhtin [Voloshinov] (1999 [1929]), em suas teorizações sobre a linguagem de modo geral. Os estudos do letramento focalizam uma nova concepção da modalidade escrita da língua na sociedade, pois, além de a entenderem na perspectiva social, a concebem como presente na vida cotidiana. Segundo Barton e Hamilton (1998), a escrita não é tomada somente como um conjunto de atividades cognitivas, e também não se limita a representações materializadas no papel. Conforme os autores, assim como todas as atividades humanas - e a escrita é uma atividade humana -, essa modalidade da língua é eminentemente social e está presente nas interações entre as pessoas.

No que diz respeito ao processo de ensino da produção textual escrita, a concepção dessa atividade como expressão do pensamento parece-nos ainda bastante vinculada a representações de base cognitivista que antecederam ${ }^{7}$ teorizações presentes na proposta do ensino operacional $e$ reflexivo da linguagem (GERALDI, 1997 [1991]), tanto quanto antecederam postulados dos documentos norteadores da educação Parâmetros Curriculares Nacionais (BRASIL - PCNs LP, 1998) e a Proposta Curricular de Santa Catarina (SC - PC - LP, 1998). A prevalência desse olhar cognitivista, em nossa compreensão, típico da segunda metade do século XX, parece estar presente também no excerto que segue, cujo foco, inferimos, é o processamento cognitivo da informação.

(5) A produção de um texto é você conseguir colocar no papel, através dessa simbologia que a gente tem, dessa forma linguística de expressão, todas aquelas ideias que estão flutuando no seu cérebro. E que você consegue fazer associações direitinho, uma palavra atrás da outra, através desse nosso código linguístico, como eu já disse, e transportála para o papel. Isso, para mim, é fazer uma produção escrita. (AM, entrevista realizada em 22/09/2011, ênfase nossa)

7 Tratamos, aqui, de precedência temporal, mas reconhecemos que correntes com ancoragens dessa ordem ainda se mantêm na atualidade, sob outros desdobramentos, hoje bastante vinculadas às neurociências (GERALDI, 2010). 
Concepções como essas nos remetem novamente às considerações de Bakhtin [Voloshinov] (1999 [1929]) acerca da corrente que o autor denomina subjetivismo individualista, como mencionamos anteriormente. Geraldi (2006 [1984]), por sua vez, entende que a escrita, nessa concepção, se torna um exercício formal no qual o aluno "transporta para o papel" as ideias de forma fragmentada. Entendemos que o processo de ensino da produção textual escrita, quando tomado prevalecentemente como expressão do pensamento, focaliza o ato de escrever em apenas uma de suas múltiplas dimensões - as implicações cognitivas -; as demais dimensões, a exemplo da dimensão interacional, estão ausentes nesse olhar. Para Antunes (2003, p. 54), sob a perspectiva da Linguística Textual, "Elaborar um texto escrito é uma tarefa cujo sucesso não se completa, simplesmente, pela codificação das ideias ou das informações, através de sinais gráficos. Ou seja, produzir um texto escrito não é uma tarefa que implica apenas o ato de escrever".

Conceber a produção textual escrita como expressão do pensamento, tal qual o faziam os adeptos do que Bonini (2002) entende como o método retórico-lógico - método cujas bases estão na gramática tradicional, com inspiração lógica -, é entendê-la como, segundo menciona o autor, um "substrato direto do raciocínio", na medida em que aprender a escrever seria aprender a organizar, na modalidade escrita da língua, o que se conhece, o que se entende, em termos de pensamento, movimento que entendemos subjacente ao excerto a seguir:

(6) [Produção textual escrita] é conseguir transmitir a ideia sem sair do foco apresentado. Tem que ter uma introdução, desenvolvimento e uma conclusão. Esse texto tem que obedecer a parágrafo, margem. Quando tem diálogo, por exemplo, nas turmas menores, eles precisam saber utilizar o diálogo e cometer o mínimo possível de erros ortográficos. (CZO, entrevista realizada em 14/09/2011, ênfase nossa)

Inferimos prevalecer, nesse excerto, a concepção da produção de textos como expressão do pensamento, mas, além disso, parece haver nele a focalização também na estrutura do texto, como é possível ver nos trechos destacados. Conforme Bonini (2002, p. 29), no método denominado pelo autor de retórico-lógico, "[...] aprender a escrever equivale a conhecer as regras gramaticais que, em última instância, valem mais como fórmulas o autor, nesse método, a estrutura textual tem relativa importância, na medida em que as técnicas de ensino da produção textual giram em torno 
dela. O autor escreve: "Quanto às técnicas de ensino, estão a serviço, fundamentalmente, da apropriação dos esquemas básicos de textos - a narração, a dissertação e a descrição. Por isso, a técnica principal é a de desenvolver o texto dentro de um esquema textual abstrato [...]" (BONINI, 2002, p. 29). Em nossa compreensão, o excerto a seguir sinaliza para concepções dessa ordem: (7) "Primeiramente, eu tenho que ter uma fonte. Tenho que ter o esqueleto de uma estrutura. Eu tenho que ler um texto antes para depois saber como é feita toda estrutura, ler o que eu vou fazer e exercitar". (RFB, entrevista realizada em 15/09/2011, ênfase nossa).

Inferimos, nesse excerto, concepções de que quem escreve deve ter conhecimento suficiente sobre o que quer escrever e, além disso, deve conhecer, de forma satisfatória, a estrutura do texto, e questão essencial na textualização são os pensamentos e conhecimentos expressos. Ainda nesse excerto, parece-nos que o conhecimento relevante é o "esqueleto" do texto, conforme é possível observar no trecho destacado, e a produção de textos escritos teria o propósito maior de "exercitar" a estrutura trabalhada. Segundo Antunes (2003), essa escrita uniforme, em que não há variações na estrutura, na organização, na sequência das partes é uma "[...] escrita sem função, artificial, mecânica, inexpressiva, descontextualizada, convertida em puro treino e exercício escolar [...]" (ANTUNES, 2003, p. 50). Ainda no que diz respeito à valorização da forma e da estrutura do texto, entendemos possível inferir, no próximo excerto, também uma focalização na produção textual escrita como expressão do pensamento conjuntamente com esses aspectos.

(8) Escrita é o aluno colocar as ideias dele, o que ele pensa a respeito de determinado tema. Ou então ele construir argumentos de acordo com a estrutura. Por exemplo, agora, eu trabalhei a estrutura de conto, o gênero conto. Então, ele teria que produzir. Às vezes eu peço parágrafo, às vezes eu peço um texto. Às vezes, eu abordava só assim questão de caracterizar ambientes, caracterizar personagens. Então, produção escrita, de acordo com a metodologia da aula, do tema abordado. Então, a gente direciona para o aluno produzir, escrever o que pensa, as ideias, estruturar no papel as ideias de acordo com uma estrutura ou simplesmente com conhecimento sobre o tema. (RT, entrevista realizada em 09/08/2011, ênfase nossa)

Ressaltamos que, nas teorizações a respeito do processo de produção textual escrita com função social, de acordo com Antunes (2009) 
e Geraldi (2010), a importância dos recursos linguísticos não é negada, mas sim, esses recursos, nessa concepção, são agenciados em favor dos processos efetivos de interação. Segundo Geraldi (2010), a proposta é que haja um movimento entre o que é interno à língua, os recursos linguísticos, e o que é externo a ela, recursos que dizem respeito ao contexto social em seu sentido mais amplo. Ainda conforme o autor, essa relação entre a língua e seu contexto permite que a compreendamos como atos que constituem enunciados, tal qual propõe Bakhtin (2010 [1979]).

Cabe ressaltar que, no excerto 8, depreendemos uma abertura para argumentação do aluno, como parecem sugerir os trechos destacados. Nos excertos anteriores a esse, a focalização parecia estar mais efetivamente na expressão do pensamento materializado em uma estrutura textual; aqui, depreendemos uma ampliação dessa concepção, conforme também entendemoshavernestesexcertos: (9) "Produzirumtextoescritoseriaexpressar as ideias, dar a sua opinião, contar fatos ocorridos, dar sugestões, argumentar. Eu acho que nesse sentido". (BPM, entrevista realizada em 23/08/2011); (10) "É colocar opiniões. Produção textual é colocar no papel o que tu pensas de determinado assunto". (LWA, entrevista realizada em 14/09/2011). Em nossa compreensão, as representações em 9 e 10 transcendem questões meramente estruturais em nome de focalizar o processo de argumentação.

Ao que parece, nessa concepção de produção textual escrita como expressão do pensamento, o conteúdo dos textos dos alunos é a pedra de toque da atividade. Inferimos a focalização dos professores no que os alunos expressam em termos de conteúdo temático, mesmo que horizontalizando essas representações para registrar o plano da argumentação. O excerto que segue, a nosso ver, insere-se nessa tendência.

(11) Produção textual é a partir do momento que a gente fala sobre algum tema. Expõe sobre algum tema. Esse tema depois de certa pesquisa porque o aluno não vai escrever de algo que ele não conheça. Então, ele vai fazer leituras, vai se informar sobre o tema e a partir daí ele vai produzir um texto. (DMIJ, entrevista realizada em 29/08/2011, ênfase nossa)

Parece depreensível desse excerto de entrevista que, nessa construção de um texto. Isso nos remete a Geraldi (1997 [1991]), quando propõe as condições para que um texto seja escrito; segundo o autor o ter o que dizer institui-se sempre em relação a outros aspectos de um texto escrito com uma finalidade sociointeracional - ter razões para dizer, ter 
para quem dizer; e escolher as estratégias para dizer. Nas concepções que emergem dos excertos registrados até aqui, o ter o que dizer tende a instituirse por si só, dissociado de outras condições implicadas na produção de um texto a exemplo das já clássicas - na academia, mas seguramente não na esfera escolar - considerações de Geraldi (1997 [1991]).

Assim, entendemos que o método retórico-lógico (BONINI, 2002) parece presente nas representações docentes discutidas até aqui, em se tratando do foco no domínio ontológico, principalmente, no que diz respeito à concepção do que é produzir um texto escrito. Nessa discussão, não podemos deixar de mencionar, porém, que parece haver outras teorizações ecoando nessas concepções, conforme depreendemos neste excerto de entrevista: (12) "Produzir um texto escrito é você concatenar as ideias e produzir alguma coisa objetiva dependendo do teu propósito com essa produção. Mas você tem que ter as ideias claras para poder expressar o teu pensamento". (VRSV, entrevista realizada em 13/09/2011, ênfase nossa). Nesse excerto, além de estar materializada a concepção de produção textual escrita como expressão do pensamento, há uma condição a mais para que se produza um texto escrito. Para esse professor, a expressão do pensamento parece estar a serviço do propósito que se tem para a produção. Entendemos que representações dessa ordem aproximamse significativamente dos estudos a respeito do fenômeno do letramento, segundo os quais utilizamos a escrita com propósitos específicos (STREET, 2003). Nessa perspectiva, todavia, há outros elementos além do propósito que se tem com o texto, como o contexto em que estamos inseridos e a função social do texto que produzimos. A relação com o contexto social parece ser um ponto em que essas concepções - aquelas depreendidas das enunciações dos excertos registrados aqui e aquelas derivadas dos estudos do letramento - se distanciam. De todo modo, porém, entendemos haver, no excerto 12, um embrião dessas representações. Barton (2010 [1994]), ao focalizar o letramento como a ecologia da escrita, concebe que as pessoas têm necessidades e propósitos ao utilizar a escrita, mas isso está intrinsecamente relacionado ao contexto social. $\mathrm{O}$ autor aponta, ainda, que o ensino dessa modalidade da língua deve ter como ponto de partida as necessidades interacionais das pessoas.

Como mencionamos, pudemos depreender nas entrevistas realizadas que, apesar de a concepção da produção textual escrita como expressão do pensamento estar prevalecentemente presente nos enunciados dos docentes participantes deste estudo, nas respostas de alguns professores 
podemos observar reverberações de outras teorizações sobre o tema, como inferimos no próximo excerto.

(13) Produção textual é o aluno conseguir colocar de forma escrita todas as suas ideias, tudo que ele aprendeu, que ele conseguiu interpretar, compreender de um texto, uma mensagem que ele quer escrever. Dependendo do gênero que ele está trabalhando, qual é o objetivo. Que ele consiga colocar no papel o objetivo do que ele quer escrever. Para quê que ele vai escrever. $O$ que ele vai escrever. Se ele está escrevendo da maneira certa, se alguém vai entender. (LSM, entrevista realizada em 01/09/2011, ênfase nossa)

Nesse excerto, parece-nos claro que o professor materializa em sua concepção implicações de diferentes teorizações. Inferimos que, a exemplo de participantes anteriormente mencionados, esse educador entende a produção de textos escritos como expressão do pensamento, no entanto parece, ainda, evocar pressupostos da chamada teoria da comunicação - o que entendemos remeter ao embrião do funcionalismo jakobsoniano -, tanto quanto evocar pressupostos de teorizações acerca dos gêneros discursivos de base bakhtiniana, as quais têm implicações, entre outras questões, nos objetivos para a produção de um texto escrito, o que nos remete às condições para a produção de textos (GERALDI, 1997 [1991]), que mencionamos anteriormente.

Além da concepção em que a produção textual escrita está estreitamente vinculada à expressão do pensamento, conforme apresentamos nesta seção, 21,3\% dos professores participantes deste estudo entendem o ato de produzir um tex to escrito sob outras perspectivas em relação ao contingente de 78,7\% daqueles que o entendem na perspectiva descrita analiticamente até aqui, tal qual mostra a Tab. 1. Esses outros professores concebem tal processo a partir de outras representações, o que nos fez uni-los em um único grupo, comportamento motivado pelo baixo número de docentes inscritos em cada qual dessas mesmas representações, as quais mencionamos a seguir.

produzir um texto escrito não está relacionado tanto ao conteúdo, conforme a concepção explicitada anteriormente; em sua compreensão a questão axial parece ser a estrutura. Apesar de os docentes que entendem a produção textual escrita como expressão de conhecimentos adquiridos demonstrarem, a partir das respostas da entrevista, também focalização na estrutura, os dois participantes de pesquisa cujas enunciações descrevemos 
nesse segundo grupo, em suas respostas à questão "Para você, o que é produção textual escrita?", não parecem materializar o foco no conteúdo; fazem-no essencialmente no que respeita à estrutura textual.

Conceber a língua sob uma perspectiva sistêmico-estrutural converge com a corrente que Bakhtin [Voloshinov] (1999 [1929]) denomina objetivismo abstrato. Nessa concepção, a cada enunciação os elementos estruturais da língua são idênticos aos elementos de outras enunciações, ou seja, segundo Bakhtin [Voloshinov] (1999 [1929]), são normativos para todas as atividades linguísticas. Para o autor, nessa corrente, há um apagamento do sujeito, que já encontra a língua pronta para ser usada. Desse modo, há separação entre língua e conteúdo ideológico, e o sujeito e sua produção comunicativa tendem a ficar à margem das discussões. Entendemos ser depreensível, no excerto de entrevista transcrito a seguir, um exemplo da concepção que, em nosso entendimento, prioriza a estrutura linguística dos textos.

(14) Para mim, seria eles [os alunos], minimamente, conseguir escrever alguma coisa que possa ser chamada de "texto". É eles saberem escrever uma crônica, um conto, uma história etc., etc., etc. Para a turma que eu estou dando aula agora, é eles produzirem alguma coisa, conseguirem escrever e a gente poder chamar de texto aquilo que eles escreveram. Que a gente consiga entender, que qualquer pessoa consiga entender. (RCS, entrevista realizada em 09/08/2011)

Embora nesse excerto haja menção à nomeação de gêneros discursivos e, ainda, o conteúdo possa suscitar uma abordagem focada na coerência textual, parece-nos que a preocupação efetiva reside na possibilidade de reconhecimento, por parte do leitor, de que o que tem diante de si é um texto. Entendemos que isso possa ser decorrente de uma preocupação evidente com o alfabetismo funcional. Talvez essa focalização provenha do fato de esse professor, possivelmente, ter diante de si alunos não inteiramente alfabetizados no segundo segmento do Ensino Fundamental, o que dados do Inaf (2009) informam acontecer no Brasil. Outro exemplo de concepção da produção de textos escritos com foco na estrutura parece se eliciar neste excerto: (15) "Eu acho que é o aluno escrever com excelência. Desenvolver todos os gêneros de produção escrita. Saber a diferença de forma, de estrutura desses diferentes tipos de gênero". (AGM, entrevista realizada em 08/08/2011).

Emerge, a nosso ver, desse excerto, o foco na estrutura, dimensão 
priorizada mesmo havendo menção aos gêneros discursivos, menção que, na verdade, parece comprometida mais efetivamente com questões de tipificação estrutural. Em nosso entendimento, a significativa complexidade do conceito de gêneros discursivos à luz da filosofia bakhtiniana e o mimetismo a que os conceitos da esfera acadêmica tendem a ser submetidos quando chegam à esfera escolar (BATISTA, 1996) são fatores que subjazem a enunciações como em 15 e que contribuem para que as representações docentes se distingam em boa medida da heurística que sustenta o ideário histórico-cultural, aporte de documentos institucionais e da maior parte da literatura científica sobre ensino de língua materna na contemporaneidade.

Esse processo de lidar com os gêneros discursivos com enfoque prioritário em sua estrutura interna parece-nos parte do perigoso movimento de objetificação dos gêneros, percurso no qual corremos o risco de nos distanciarmos das propriedades que justificam o conceito em sua origem: o fato de serem tipos relativamente estáveis de enunciados que instituem interações humanas social e historicamente situadas, tal qual propõe Bakhtin (2010 [1952/53]). De acordo com Geraldi (2010), todo gênero possui uma estrutura, mas o conhecimento dessa estrutura por si só não justifica e não sustenta a produção do texto no gênero. Segundo o autor,

Escrever não é uma atividade que segue regras previstas, como resultados de antemão antecipados. Escrever um texto exige sempre que o sujeito nele se exponha, porque ele resulta de uma criação. Por isso cada texto difere do outro, apesar de tratar do mesmo tema e estar expresso na configuração de um mesmo gênero. (GERALDI, 2010, p. 98)

Mais uma vez, em nosso entendimento, a despeito de eventual mimetismo, estamos depreendendo reverberações do ideário histórico acerca do tema na literatura da área. Inferimos que essas interpenetrações entre concepções tidas como tradicionais e concepções presentes nessas discussões decorrem da possível ainda não incorporação efetiva desse ideário nas concepções docentes. Gonçalves (2011), em dissertação de mestrado sobre concepções de professores acerca da alfabetização, visibilizou o tempo que teorizações da esfera acadêmica demandam em se tratando da apropriação por parte de docentes na esfera escolar. Batista (1996) também discute os meandros desse processo de encontro entre a esfera acadêmica e a esfera escolar, refletindo sobre como as teorizações, quando chegam à esfera escolar, tendem a se imbricar com o já dado 
naquelas ambientações, ganhando contornos diferentes daqueles que as caracterizavam nas produções científicas.

Além dessa concepção, que entendemos como comprometida com a estrutura do texto, dois professores entendem que produzir um texto escrito é uma forma de se comunicar por meio da modalidade escrita da língua. Produzir um texto escrito como forma de comunicação parece ser, nas enunciações desses docentes, a função de um texto, conforme depreendemos neste excerto: (16) "A produção textual escrita é uma forma de se comunicar através da escrita porque, se houve a comunicação, atingiu o objetivo". (MRSM, entrevista realizada em 24/08/2011).

Conceber a língua e, por extensão a modalidade escrita, como instrumento de comunicação implica entender que a linguagem é um conjunto de signos e códigos que se combinam de acordo com regras e que formam uma mensagem enviada de um emissor a um receptor (GERALDI, 2006 [1984]). Não podemos negar que há, nessa concepção, um caráter social na produção textual escrita; no entanto esse caráter social parece-nos bastante circunscrito, dentre outras tantas razões, por não considerar a agentividade daquele que recebe a mensagem e por lidar com a assepsia do contexto interacional. Trata-se, em nossa compreensão, tal qual já mencionamos, do embrião do funcionalismo jakobsoniano (JAKOBSON, 1974). O interlocutor, nessa perspectiva, não é visto como sujeito que influencia no processo de escritura de um texto, concepção historicamente posterior ao pensamento funcionalista-estruturalista ${ }^{8}$. Consideradas especificidades

\footnotetext{
8 Tomamos funcionalismo, aqui, na perspectiva do Círculo Linguístico de Praga e, mais especificamente, do pensamento de Roman Jakobson, e não na heterogeneidade das correntes funcionalistas contemporâneas.
}

dessa historicidade das teorizações, a mensagem, no caso o texto, especificidades dessa historicidade das teorizações, a mensagem, no caso o texto, é entendida pelo ideário funcionalista-estruturalista como um sistema de signos que se combinam por meio de regras já definidas e não por um sistema de signos que são combinados de diferentes formas dependendo das estratégias do dizer que são utilizadas.

Segundo Bonini (2002), o método pelo qual os textos são escritos somente com função comunicativa é tomado como método textualcomunicativo. De acordo com o autor, os fundamentos didáticos desse método são quase os mesmos do método retórico-lógico, mas sua filosofia se distingue. $\mathrm{O}$ autor aponta que o produtor de textos "[...] não é mais visto 80 
como assimilador de regras, mas como alguém que precisa desenvolver uma capacidade textual, fundamental para que ele seja um comunicador" (BONINI, 2002, p. 30). Ainda de acordo com Bonini (2002, p. 31), nesse método, "O desenvolvimento de conhecimentos metalinguísticos relativos aos mecanismos que formam o texto passa a ser o ponto norteador". O objetivo das produções de textos escritos, conforme o autor, nessa perspectiva, é desenvolver no aluno seu papel de comunicador.

Além das concepções já mencionadas - e ainda dentro do percentual de $21,3 \%$ dos participantes de pesquisa cujas enunciações em resposta à questão aqui discutida foram nomeadas outras concepções -, um professor concebe que produzir um texto escrito é escrever algo com um objetivo claro, com um destinatário e em determinado gênero discursivo, como observamos no próximo excerto.

(17) Produção textual escrita é qualquer texto que o aluno consiga produzir que tenha um objetivo claro, um destinatário, que ele tenha ciência de que aquilo que ele está produzindo é um texto para servir para alguma coisa, atingir algum objetivo. E pode ser qualquer gênero textual, desde um bilhete. (MBZA, entrevista realizada em 31/08/2011)

Inferimos uma possível vinculação com a teoria da comunicação, que mencionamos anteriormente, pois a pessoa a quem o texto se dirige ainda é o destinatário. Ressaltamos, entretanto, que isso poderia ser compreendido apenas como uma terminologia utilizada pelo professor. Como podemos observar nesse excerto, o conteúdo dessa enunciação parece se aproximar do ideário presente nos documentos norteadores da educação e das teorizações da área. A concepção de que, ao produzir textos, os produzimos materializados em gêneros discursivos remete a reverberações de teorizações de Bakhtin (2010 [1952/53]) em que o autor entende os gêneros como instituidores das interações humanas. $\mathrm{O}$ conceito de gêneros em Bakhtin (2010 [1952/53]) implica conceber que o texto, como enunciado, é essencial para as atividades humanas. Essa compreensão, no caso do ensino da produção textual escrita, possibilita que esse processo, considerando que somos produtores de linguagem, enunciados e discursos, esteja na sala de aula com o objetivo de ampliar as práticas de uso da língua dos alunos.

Ainda no âmbito das outras concepções, que correspondem a $21,3 \%$ do total de entrevistados, as representações de um dos professores 
remetem a compreensões que se difundem no senso comum, ou seja, que produzir um texto escrito é veículo de ascensão social, mecanismo para compreender melhor o mundo, como observamos a seguir, o que nos remete ao mito do alfabetismo (GRAFF, 1994) e às simplificações, objeto da crítica de Britto (2003), sobre propriedades socialmente redentoras dos domínios da escrita. Eis o excerto: (18) "Eu definiria como uma maneira de compreender melhor o mundo e como uma maneira de melhorarmos o mundo de certa forma. Uma maneira de ascensão também. Uma pessoa que escreve melhor, de certa forma, ela ascende mais". (TCR, entrevista realizada em 11/08/2011, ênfase nossa).

Graff (1994) chama atenção para concepções de natureza causalconsecutiva em se tratando das relações entre domínios da escrita e empregabilidade, desenvolvimento e afins. Já Britto (2003) atenta para as implicações de representações da ordem de "levar luz à escuridão", como se os domínios da escrita não tivessem implicações sociais, políticas e econômicas mais amplas. Kalman (2003), enfim, atenta para o fato de que, além das disposições individuais, os domínios da escrita têm implicações de acessibilidade social.

Ao observarmos esse excerto, inferimos que a produção textual escrita, nessa perspectiva, parece estar relacionada com aspectos formais e estruturais da língua. A pessoa que quer ascender socialmente deve escrever de acordo com os padrões valorizados. A concepção de escrita que subjaz aqui parece, tal qual já mencionamos anteriormente, aproximar-se do que Street (1984) denomina modelo autônomo de letramento. Segundo o autor, nesse modelo, a escrita estaria separada do contexto social, sendo tomada como imanente, de forma que o domínio da modalidade, em si mesmo, poderia provocar mudanças nas representações cognitivas do sujeito. Street (1984) discute alguns estudos que relaciona a esse modelo e, para ele, esses estudos pressupõem que há relações causais entre domínio da escrita e desenvolvimento das nações. Nessa concepção, sociedades consideradas "letradas" seriam mais desenvolvidas, pois a escrita estaria associada com progresso, civilização, liberdade individual e mobilidade social. $\mathrm{O}$ autor critica essas considerações, pois segundo ele, não existe nenhuma sociedade que seja "iletrada" de fato, pois até mesmo nas sociedades consideradas menos desenvolvidas há, em alguma medida, interpenetrações entre as modalidades oral e escrita da língua. Kleiman (2010 [1995]) complementa, ainda, que não existe nenhuma possível comprovação de relações causais/ consecutivas entre escolarização e desenvolvimento econômico. 
Por fim, além das concepções descritas analiticamente, três professores não definiram especificamente o que entendem como sendo a produção textual escrita, o que consideramos como questão não respondida e não analisamos nesta seção, em que buscamos responder a nossa questão de pesquisa sobre o que seria a produção textual escrita para os docentes participantes deste estudo.

\section{Considerações finais}

Quer sob o ponto de vista dos documentos parametrizadores da educação em linguagem - Parâmetros Curriculares Nacionais (BRASIL PCNs LP, 1998) e a Proposta Curricular de Santa Catarina (SC - PC - LP, 1998) - quer sob o ponto de vista de teorizações acadêmicas, a exemplo da proposta do ensino operacional e reflexivo da linguagem (GERALDI, 1997 [1991]), no que diz respeito à produção textual escrita importa considerar que um texto é o resultado de uma atividade discursiva na qual alguém diz algo a alguém, algo que faça algum sentido e que tenha sido desenvolvido mediante as condições de produção de um texto (GERALDI, 1997 [1991]). Nessa perspectiva, produzir um texto escrito é uma atividade interativa, dialógica, no sentido bakhtiniano do termo, um processo por meio do qual estabelecemos interações com o outro.

É possível depreender, por meio das entrevistas realizadas, das quais transcrevemos diversos excertos neste artigo, que a concepção da produção de textos escritos de grande parte dos professores participantes do estudo parece distinguir-se, em sua maioria, dessas representações. Observamos, todavia, reverberações desses postulados nas concepções docentes, o que sugere que as discussões que têm lugar na academia desde o surgimento da nova crítica ao ensino da língua (BRITTO, 1997) têm perpassado o espaço escolar, inferimos, por meio de cursos de formação continuada ou até mesmo na formação inicial desses docentes, sem terem sido, no entanto, efetivamente incorporadas - mais uma vez o tempo demandado para que novas teorizações cheguem à esfera escolar (GONÇALVES, 2011), tanto quanto o mimetismo a que tais teorizações estão sujeitas em relação a representações que vigem nessa mesma esfera (BATISTA, 1996) .

Ressaltamos que não entendemos tais distinções como lacunas ou equívocos nas concepções dos docentes participantes deste estudo, mas vemos a necessidade de um processo de formação inicial e continuada que 
propicie a efetiva apropriação desse ideário. Assim, procuramos auscultar ecos que existem e não lacunas que se estabelecem; logo, nosso foco é a eventual presença desse ideário.

\section{Referências}

ANTUNES, I. Aula de português - encontro \& interação. São Paulo: Parábola Editorial, 2003.

. Língua, texto e ensino. São Paulo: Parábola Editorial, 2009.

BAKHTIN, M. [VOLOSCHINOV]. Marxismo e filosofia da linguagem: problemas fundamentais do método sociológico na ciência da linguagem. 9. ed. São Paulo: Hucitec, 1999 [1929].

BAKHTIN, M. Os gêneros do discurso. In:. Estética da criação verbal. Tradução de Paulo Bezerra. 4. ed. São Paulo: Martins Fontes, 2010 [1952/53; 1979]. p. 261-306.

BAQUERO, M. A pesquisa quantitativa nas Ciências Sociais. Porto Alegre: Editora da UFRGS, 2009.

BARTON, D. Literacy: an introduction to the ecology of written language. Oxford: Blackweell, 2010 [1994].

BARTON, D. HAMILTON, M. Local literacies. London: Routledge, 1998.

BASSO, I. S. Significado e sentido do trabalho docente. Caderno Cedes, Campinas, v. 44, n. 19, p.19-32, 1998. Disponível em: <http://www.scielo. br/scielo.php?script=sci_arttext\&pid=S0101-32621998000100003\&lng $=p$ t\&nrm=iso>. Acesso em: 08 mar. 2012.

BATISTA, A. A. G. Aula de Português: discurso e saberes escolares. São Paulo: Martins Fontes, 1996.

BONINI, A. Metodologias do ensino de produção textual: a perspectiva da enunciação e o papel da Psicolinguística. Perspectiva, Florianópolis, v. 20, n. 1, p.23-47, 2002. Disponível em: <http://www.periodicos.ufsc.br/index. 
php/perspectiva/article/view/10366. >. Acesso em: 22 mar. 2012.

BRASIL. Instituto Paulo Montenegro.Indicador de Alfabetismo Funcional: principais resultados. Disponível em: <http://www.ipm.org.br/download/ inaf_brasi12009_relatorio_divulgacao_final.pdf>. Acesso em: 08 fev. 2012.

BRASIL. SEF. Parâmetros curriculares nacionais: terceiro e quarto ciclos do ensino fundamental: língua portuguesa. Brasília: MEC/SEF, 1998.

BRITTO, L. P. L. A sombra do caos: ensino de língua x tradição gramatical. Campinas, SP: Mercado de Letras, 1997.

. Contra o consenso: cultura escrita, educação e participação. Campinas, SP: Mercado das Letras, 2003.

GERALDI, J. W. Concepções de linguagem e ensino de português. In: p. 39-46.

. Escrita, uso da escrita e avaliação. In: (org.). O texto na sala de aula. São Paulo: Ática, 2006 [1984]. p. 127-131.

. Portos de passagem. 2. ed. São Paulo: Martins Fontes, 1997 [1991].

GONÇALVES, F. C. Alfabetização sob o olhar dos alfabetizadores: um estudo sobre essencialidades, valorações, fundamentos e ações no ensino da escrita na escola. Dissertação (Mestrado) - Programa de Pós-graduação em Linguística - Universidade Federal de Santa Catarina, Florianópolis, 2011.

GRAFF, H. Os labirintos da alfabetização: reflexões sobre o passado e o presente da alfabetização. Porto Alegre: Artes Médicas, 1994.

JAKOBSON, R. Linguística e comunicação. São Paulo: Cultrix, 1974.

KALANTZIS, M.; COPE, B. Multiliteracies. Londes/New York: Routledge, 2006.

KALMAN, J. El acceso a la cultura escrita: La participación social y la apropriación de conocimientos em eventos cotidianos de lectura y 
escritura. Revista Mexicana de Investigación Educativa, México, v. 17, n. 8, p.37-66, 2003. Disponível em: <http://www.comie.org.mx/v1/revista/ visualizador.php? articulo=ART00362\&criterio $=$ http://www.comie.org . $\mathrm{mx} /$ documentos/rmie/v08/n017/pdf/rmiev08n17scB02n02es.pdf $>$. Acesso em: 20 mar. 2012.

KLEIMAN, A. Modelos de letramento e as práticas de alfabetização na escola. In: _. (Org) Os significados do letramento: uma nova perspectiva sobre a prática da escrita. Campinas, SP: Mercado dos Letras, 2001 [1995], p.15-64.

LAPO, F. R; BUENO, B. O. Professores, desencanto com a profissão e abandono do magistério. Cadernos de Pesquisa, São Paulo, n. 118, p.6588, mar. 2003. Disponível em: <http://www.scielo.br/pdf/cp/n118/16830. pdf $>$. Acesso em: 15 mar. 2012.

MASON, J. Qualitative researching. London: SAGE Publications, 1996.

RABELO, A. O.; MARTINS, A. M. A mulher no magistério brasileiro: um histórico sobre a feminização do magistério. In: VI CONGRESSO LUSO-BRASILEIRO DE HISTÓRIA DA EDUCAÇÃO: PERCURSOS E DESAFIOS DA PESQUISA E DO ENSINO DE HISTÓRIA DA EDUCAÇÃO, 2006, Uberlândia. Anais. Uberlândia: Faced/UFU, 2006. p. 6167 - 6176. Disponível em: <http://www.faced.ufu.br/colubhe06/anais/ arquivos/556AmandaO.Rabelo.pdf>. Acesso em: 19 mar. 2012.

SANTA CATARINA. SEED. Proposta curricular de Santa Catarina: educação infantil, ensino fundamental e médio: disciplinas curriculares. Florianópolis: COGEN, 1998.

SILVEIRA, A. P. K. da. Formação continuada em Língua Portuguesa: Crenças, Expectativas e Saber. In: IX CONGRESSO NACIONAL DE EDUCAÇÃO DA PUCPR - EDUCERE; III CONGRESSO IBEROAMERICANO SOBRE VIOLÊNCIA NAS ESCOLAS - CIAVE, 2009, Curitiba. Anais. Curitiba: PUCPR, 2009. p. 10807 - 10821. Disponível em: 90 Leia Escola, Campina Grande, v. 12, n. 2, 2012 - ISSN 1518-7144

<http://www.pucpr.br/eventos/educere/educere2009/anais/pdf/3325_1495. 
pdf>. Acesso em: 05 mar. 2012.

STREET, B. Abordagens alternativas ao letramento e desenvolvimento. Apresentado durante a Teleconferência Unesco Brasil sobre 'Letramento e Diversidade', outubro de 2003.

. Literacy in theory and practice. Cambridge: CUP, 1984. VYGOTSKY, L. A formação social da mente. São Paulo: Martins Fontes, 2007 [1978].

Recebido em: agosto de 2012.

Aprovado em: novembro de 2012 